\title{
A TEORIA SOCIOLÓGICA DE NORBERT ELIAS E A PRODUÇÃO CIENTÍFICA EM EDUCAÇÃO FÍSICA NO BRASIL: UMA REVISÃO SISTEMÁTICA ${ }^{1}$
}

Recebido em: 02/11/2018

Aceito em: 12/09/2019

\author{
Adriely Gonçalves Orlando ${ }^{2}$ \\ Universidade Estadual de Maringá \\ Maringá - PR - Brasil \\ Fabiane Castilho Teixeira ${ }^{3}$ \\ Centro Universitário de Maringá (UNICESUMAR) \\ Maringá - PR - Brasil \\ Vinicius Machado de Oliveira ${ }^{4}$ \\ Claudio Kravchychyn ${ }^{5}$ \\ Juliano de Souza ${ }^{6}$ \\ Ieda Parra Barbosa-Rinald $i^{7}$ \\ Universidade Estadual de Maringá \\ Maringá - PR - Brasil
}

RESUMO: A revisão sistemática objetivou identificar os conceitos da teoria de Norbert Elias e o modo com que têm sido acionados nas produções científicas em Educação Física no Brasil, publicadas no período de 2007 a 2018. Foram mapeadas as bases de dados Lilacs, Scielo, Scopus e Web of Science, complementada por busca manual realizada em periódicos A2, B1 e B2 da área e 16 artigos foram identificados. A análise descritiva e o método de análise de conteúdo subsidiaram o tratamento dos dados. Os resultados identificaram conceitos chaves da teoria empregada nos artigos. Conclui-se que, apesar de a comunidade científica operar com conceitos eliasianos, o alcance deste referencial na área enfatiza, sobretudo, dinâmicas que envolvem o fenômeno esportivo, estando, esse quadro em aberto para subsidiar o tratamento de outros objetos caros à Educação Física.

PALAVRAS CHAVE: Produção Científica. Educação Física. Sociologia.

\footnotetext{
${ }^{1}$ Agradecemos à Fundação Araucária pelo apoio para a realização dessa pesquisa.

${ }^{2}$ Graduada em Educação Física pela Universidade Estadual de Maringá - PR

${ }^{3}$ Professora do departamento de Educação Física da UNICESUMAR.

${ }^{4}$ Mestre em Educação Física pelo Programa de Pós Graduação Associado UEM/UEL.

${ }^{5}$ Professor Adjunto do Departamento de Educação Física da Universidade Estadual de Maringá - PR.

${ }^{6}$ Professor do Programa de Pós-Graduação Associado em Educação Física UEM-UEL.

${ }^{7}$ Professora do Programa de Pós-Graduação Associado em Educação Física UEM-UEL.
} 


\section{NORBERT ELIAS' SOCIOLOGICAL THEORY AND SCIENTIFIC PRODUCTION IN PHYSICAL EDUCATION IN BRAZIL: A SYSTEMATIC REVIEW}

ABSTRACT: The objective of the systematic review was to identify which concepts of Norbert Elias' theory and how they have been activated in the scientific productions in Physical Education in Brazil, published in the period from 2007 to 2018. The Lilacs, Scielo, Scopus and Web of Science databases were mapped, complemented with a manual search conducted in periodicals A2, B1 and B2 of the area and 16 articles were identified. The descriptive analysis and the method of content analysis subsidized the treatment of the data. The results identified key concepts of the theory employed in the articles. It is concluded that, although the scientific community operates with eliasian concepts, the scope of this reference in the area emphasizes, above all, dynamics that involve the sport phenomenon, being this open framework to subsidize the treatment of other expensive objects to Physical Education.

KEYWORDS: Scientific Production. Physical Education. Sociology.

\section{Introdução}

Apesar da divulgação do referencial teórico do sociólogo alemão Norbert Elias ainda ser incipiente na produção científica em Educação Física no Brasil, é possível notar um crescente interesse da comunidade científica, conforme apontam Medeiros e Godoy (2009); Góis Junior; Lovisolo e Nista-Piccolo (2013), em se apropriar desse referencial teórico para tratar objetos de pesquisas pertinentes à área.

Foi com base, portanto, nessa realidade social que realizamos a pesquisa empírica que deu origem a este artigo, uma vez que identificamos a relevância de mapear a produção científica em Educação Física que buscou subsídios no arcabouço teórico do sociólogo alemão, para levar a efeito o desenvolvimento de pesquisas na área.

A propósito, uma pesquisa realizada por Medeiros e Godoy (2009), verificou o emprego da teoria eliasiana em artigos científicos publicados na Revista Brasileira de Ciências do Esporte (RBCE), no período de 1979 a 2007. As autoras chamam a atenção para a forma genérica e pontual com a qual a teoria de Elias foi empregada nos 
trabalhos, pois, das 12 publicações localizadas e que fizeram uso desse referencial, apenas cinco discutiam amplamente mais de um conceito elaborado pelo sociólogo.

Frente ao cenário apresentado, destacamos que os subsídios da teoria sociológica em tela motivaram o desenvolvimento dessa pesquisa, em particular porque a mesma é relevante para o campo da Educação Física por agregar possibilidades e significados à compreensão das relações sociais constituídas em diferentes contextos. Além disso, a verificação de como tem se dado a recepção e apropriação deste referencial teórico é válida, pois oferece elementos concretos acerca da sofisticação analítica que o campo da Educação Física no Brasil vem construindo nessas últimas décadas, sobretudo, ao estreitar suas relações com o campo das Ciências Humanas e Sociais.

Não podemos deixar de mencionar que Elias foi responsável pelo desenvolvimento de uma teoria social, que alargou o campo dos estudos sociológicos inclinados a desvendar os processos sociais, as relações estruturais e configuracionais entre sujeitos e os fatos sociais (SILVA; CERRI, 2013).

No presente artigo, procuramos somar elementos a este cenário e assumimos como norte investigativo identificar [1] que conceitos da teoria de Norbert Elias e [2] o modo com que têm sido acionados nas produções científicas em Educação Física no Brasil, publicadas em periódicos da área no período de 2007 a 2018.

\section{Metodologia}

O método que elencamos para o desenvolvimento da pesquisa foi a revisão sistemática de literatura (THOMAS; NELSON; SILVERMAN, 2012; GOMES; 
CAMINHA, 2014), uma forma de pesquisa que utiliza como fonte de dados a literatura disponível e relevante sobre determinado tema.

Dentro desse contexto, realizamos as buscas nas bases de dados Lilacs, Scielo, Scopus, Web of Science, as quais constituíram a fonte de dados. Os termos de busca empregados foram: "Elias", "Sociologia" "Processo Civilizador", "Educação Física" "Interdependência", "Configuração", além dos operadores booleanos: "AND” e "OR", utilizados para conectar os termos de busca.

Como critérios de inclusão foram considerados: artigos científicos publicados no período entre 2007 e 2018 nas bases de dados selecionadas e pesquisas nacionais sobre essa temática. Já como critérios de exclusão foi definido o seguinte: artigos científicos que não foram publicados em periódicos da Educação Física e artigos de revisão sistemática/integrativa e de estado da arte. Cabe mencionar que o período delimitado para a coleta de dados foi selecionado considerando o ascendente interesse dos pesquisadores do campo da Educação Física neste referencial teórico, conforme passível reforçar ao contrastarmos a posteriori nosso trabalho de mapeamento com aquele realizado pioneiramente por Medeiros e Godoy (2009).

A busca realizada pré-selecionou 82 trabalhos, distribuídos da seguinte forma nas bases de dados: na base de dados Lilacs encontramos 18 artigos, sendo que sete contemplaram os critérios de inclusão, e foram selecionados para a leitura dos títulos, resumos e palavras-chave. Na sequência, a busca na base de dados Scielo localizou 24 artigos, que após a aplicação dos mesmos critérios resultou em cinco trabalhos para a verificação inicial. Na base de dados Web of Science foram localizados 27 artigos, e apenas um foi selecionado. Já na base de dados Scopus encontramos 13 trabalhos, sendo 
dois eleitos para essa análise. Dessa forma, 15 artigos foram selecionados para a leitura dos títulos, resumos e palavras-chave.

Após essa verificação e com a aplicação dos critérios de exclusão foram eleitas 13 publicações para a leitura na íntegra, sendo seis da base de dados Lilacs, quatro da base de dados Scielo, uma da base de dados Web of Science e duas da base de dados Scopus. Identificamos dois artigos duplicados, localizados nas bases de dados Scielo e na base de dados Lilacs, restando 11 publicações para análise.

Dando continuidade, fizemos uma busca manual a fim de conferir se haveriam outros estudos que não foram recuperados nas bases de dados e que contemplassem o foco da pesquisa. A busca foi realizada em periódicos A2, B1 e B2 da área. Esta busca identificou oito artigos, que após a leitura na íntegra e aplicação dos critérios de inclusão e exclusão, resultou em cinco artigos para comporem à amostra do estudo. Desta forma, a amostra final da pesquisa foi composta por 16 artigos científicos. A figura 1 demonstra o fluxograma que representa o processo de revisão sistemática. 
Figura 1: Fluxograma do processo de revisão sistemática

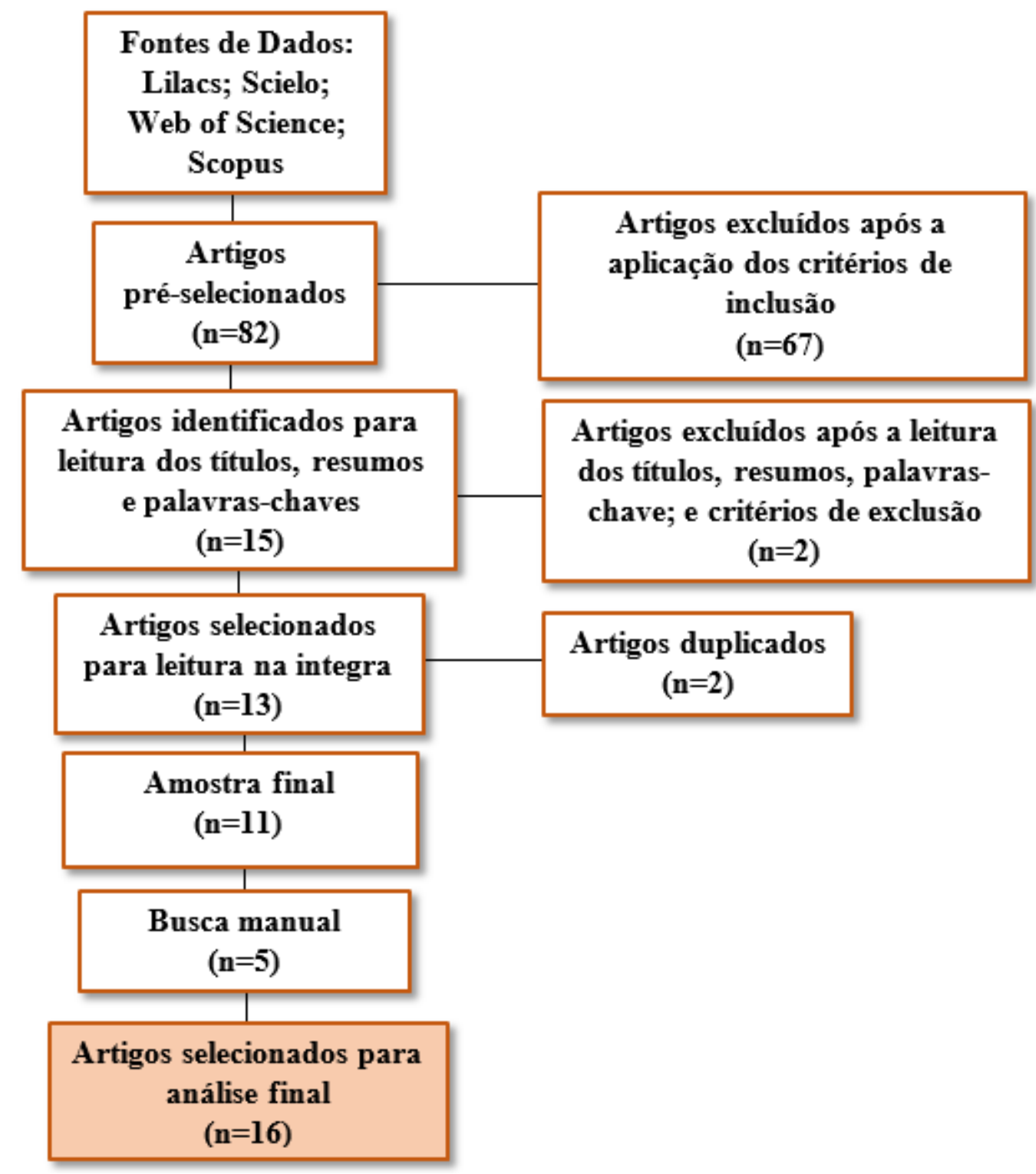

Fonte: Os autores

Fizemos uma verificação da lista de referências indicada em cada um dos artigos, com o intuito de verificar se haveriam outros estudos que pudessem complementar a pesquisa. Entretanto, nenhuma produção foi encontrada.

Para o tratamento dos dados recorremos à análise descritiva, e o mapeamento dos conceitos foi realizado com base no método de análise de conteúdo (BARDIN, 2011), do tipo categorial, aqui eleito por remeter a procedimentos sistemáticos e 
Adriely Gonçalves Orlando,

A Teoria Sociológica de Norbert Elias e a Produção Científica...

Fabiane Castilho Teixeira, Vinicius Machado de Oliveira,

Claudio Kravchychyn, Juliano de Souza

Ieda Parra Barbosa-Rinaldi

objetivos da descrição de conteúdos de mensagens, além de possibilitar uma leitura e

análise mais profunda dos conteúdos verificados.

\section{Resultados e Discussões}

O quadro que segue oferece um panorama sintético das produções materializadas nos periódicos científicos da Educação Física no Brasil que, no período de 2007 a 2018, fizeram uso do referencial teórico de Norbert Elias.

\section{Quadro 1: Produções científicas em Educação Física no Brasil que fizeram uso do referencial teórico de Norbert Elias (2007-2018)}

\begin{tabular}{|c|c|c|c|}
\hline $\begin{array}{c}\text { TÍTULO/ } \\
\text { AUTORES }\end{array}$ & OBJETIVO & METODOLOGIA & PRINCIPAIS RESULTADOS \\
\hline $\begin{array}{l}\text { Futebol, escape e } \\
\text { mímesis: um estudo } \\
\text { sobre representações } \\
\text { sociais. }\end{array}$ & \multirow{2}{*}{$\begin{array}{l}\text { Revelar a relação entre } \\
\text { futebol, escape, mímesis } \\
\text { e o cotidiano, por } \\
\text { intermédio da teoria de } \\
\text { escape de Norbert Elias e } \\
\text { seus percussores. }\end{array}$} & \multirow{2}{*}{$\begin{array}{l}\text { Pesquisa qualitativa, } \\
\text { de cunho descritivo. } \\
\text { Utilizou entrevista } \\
\text { semiestruturada. }\end{array}$} & \multirow{2}{*}{$\begin{array}{l}\text { A partir dos compromissos da } \\
\text { vida adulta, os homens precisam } \\
\text { de uma forma de escape para } \\
\text { liberar o estresse e as tensões, } \\
\text { sendo a prática do futebol uma } \\
\text { delas. }\end{array}$} \\
\hline Valentin e Cavichiolli & & & \\
\hline $\begin{array}{l}\text { Jogos eletrônicos e a } \\
\text { busca da excitação. }\end{array}$ & \multirow[b]{2}{*}{$\begin{array}{l}\text { Discutir uma possível } \\
\text { forma de interpretar os } \\
\text { jogos eletrônicos como } \\
\text { forma de lazer. }\end{array}$} & \multirow[b]{2}{*}{$\begin{array}{l}\text { Pesquisa qualitativa/ } \\
\text { quantitativa, de } \\
\text { cunho descritivo. } \\
\text { Utilizou questionário } \\
\text { online. }\end{array}$} & \multirow{2}{*}{$\begin{array}{l}\text { Os jogos eletrônicos estão em } \\
\text { pleno desenvolvimento, por } \\
\text { proporcionarem o mesmo nível } \\
\text { de prazer das atividades } \\
\text { realizadas em ambientes } \\
\text { externos e reduzir a exposição a } \\
\text { riscos reais. }\end{array}$} \\
\hline Reis e Cavichiolli & & & \\
\hline $\begin{array}{l}\text { A constituição de um } \\
\text { subcampo do esporte: } \\
\text { o caso do Taekwondo }\end{array}$ & \multirow{2}{*}{$\begin{array}{lr}\text { Discutir a relação } & \text { do } \\
\text { Taekwondo com } & \text { o } \\
\text { esporte moderno e } & \text { seu } \\
\text { processo } & \\
\text { esportivização. }\end{array}$} & \multirow{2}{*}{$\begin{array}{l}\text { Pesquisa qualitativa, } \\
\text { de cunho descritivo. } \\
\text { Utilizou entrevista } \\
\text { semiestruturada. }\end{array}$} & \multirow{2}{*}{$\begin{array}{l}\text { O Taekwondo nasceu de ruptura } \\
\text { com valores de ordem } \\
\text { filosófica, resultando em um } \\
\text { processo não planejado, com o } \\
\text { objetivo de alavancar uma } \\
\text { dinâmica de valorização social } \\
\text { por intermédio de conflitos. }\end{array}$} \\
\hline $\begin{array}{l}\text { Pimenta } \\
\text { Júnior }\end{array}$ & & & \\
\hline 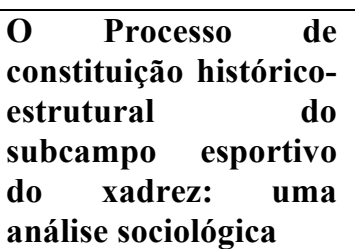 & \multirow{2}{*}{$\begin{array}{l}\text { Problematizar } \\
\text { continuidades e rupturas } \\
\text { no processo de } \\
\text { constituição de uma } \\
\text { "história } \\
\text { relativamente } \\
\text { do xadrez. }\end{array}$} & \multirow[t]{2}{*}{$\begin{array}{l}\text { Pesquisa } \\
\text { bibliográfica de } \\
\text { cunho histórico- } \\
\text { sociológico. }\end{array}$} & \multirow{2}{*}{$\begin{array}{l}\text { Revelaram-se os processos de } \\
\text { mercantilização } \\
\text { espetacularização } \\
\text { passatempos presentes no } \\
\text { interior das sociedades inglesa e } \\
\text { norte-americana. }\end{array}$} \\
\hline $\begin{array}{l}\text { Souza; Starepravo e } \\
\text { Marchi Júnior }\end{array}$ & & & \\
\hline $\begin{array}{l}\text { A teoria dos jogos } \\
\text { competitivos } r \text { de } \\
\text { Norbert Elias como } \\
\text { alternativa à leitura } \\
\text { das políticas públicas } \\
\text { de esporte e lazer no } \\
\text { Brasil }\end{array}$ & \multirow[t]{2}{*}{$\begin{array}{l}\text { Apresentar } \\
\text { possibilidades de leitura } \\
\text { de políticas públicas de } \\
\text { esporte e lazer, de acordo } \\
\text { com a Teoria dos Jogos } \\
\text { Competitivos de Norbert } \\
\text { Elias. }\end{array}$} & \multirow[t]{2}{*}{$\begin{array}{l}\text { Pesquisa qualitativa, } \\
\text { de cunho descritivo. }\end{array}$} & \multirow[t]{2}{*}{$\begin{array}{l}\text { Os jogos competitivos podem } \\
\text { ser empregados como } \\
\text { ferramentas para a compreensão } \\
\text { dos fenômenos sociais. Podem } \\
\text { contribuir para o entendimento } \\
\text { da área de políticas públicas de } \\
\text { esporte e lazer. }\end{array}$} \\
\hline $\begin{array}{l}\text { Starepravo; Souza e } \\
\text { Marchi Júnior }\end{array}$ & & & \\
\hline
\end{tabular}


Adriely Gonçalves Orlando,

A Teoria Sociológica de Norbert Elias e a Produção Científica...

Fabiane Castilho Teixeira, Vinicius Machado de Oliveira,

Claudio Kravchychyn, Juliano de Souza

Ieda Parra Barbosa-Rinaldi

\begin{tabular}{|c|c|c|c|}
\hline $\begin{array}{l}\text { Processo civilizador: } \\
\text { apontamentos } \\
\text { metodológicos na } \\
\text { historiografia } \\
\text { Educação Física }\end{array}$ & \multirow[t]{2}{*}{$\begin{array}{l}\text { Analisar a utilização do } \\
\text { modelo eliasiano em } \\
\text { problemas de pesquisa } \\
\text { no campo de História da } \\
\text { Educação Física. }\end{array}$} & \multirow[t]{2}{*}{$\begin{array}{l}\text { Pesquisa } \\
\text { bibliográfica. }\end{array}$} & \multirow{2}{*}{$\begin{array}{l}\text { A aplicação da teoria de Elias } \\
\text { na área de História da Educação } \\
\text { Física ainda ocorre de forma } \\
\text { superficial, sem definição de } \\
\text { critérios de análise. A } \\
\text { historiografia da área deve fazer } \\
\text { maior apropriação dos estudos } \\
\text { do sociólogo. }\end{array}$} \\
\hline $\begin{array}{l}\text { Góis Junior; Lc } \\
\text { Nista-Piccolo }\end{array}$ & & & \\
\hline $\begin{array}{l}\text { A guerra fria e a final } \\
\text { do campeonato } \\
\text { mundial de xadrez de } \\
\text { 1972: algumas } \\
\text { possibilidades } \\
\text { analíticas } \\
\text { correlacionadas }\end{array}$ & \multirow{2}{*}{$\begin{array}{l}\text { Estabelecer relações do } \\
\text { campo esportivo para } \\
\text { com as contingências } \\
\text { socioculturais e políticas, } \\
\text { abordando } \\
\text { especificamente o seu } \\
\text { envolvimento com a final } \\
\text { do campeonato mundial } \\
\text { de xadrez. }\end{array}$} & \multirow[t]{2}{*}{$\begin{array}{l}\text { Pesquisa qualitativa, } \\
\text { de cunho descritivo. }\end{array}$} & \multirow{2}{*}{$\begin{array}{l}\text { O "match do século" pode ser } \\
\text { encarado como um confronto } \\
\text { mimético, que gerou nos } \\
\text { indivíduos uma carga de } \\
\text { excitação fornecida pelo quadro } \\
\text { imaginário de uma guerra entre } \\
\text { dois extremos, a qual não se } \\
\text { realizou nos "fronts" de batalha, } \\
\text { mas em palcos alternativos. }\end{array}$} \\
\hline Souza e Marchi Júnior & & & \\
\hline $\begin{array}{l}\text { As configurações do } \\
\text { futebol brasileiro: } \\
\text { análise da trajetória } \\
\text { de um treinador }\end{array}$ & \multirow{2}{*}{$\begin{array}{l}\text { Analisar a trajetória de } \\
\text { um treinador de futebol e } \\
\text { levantar informações que } \\
\text { auxiliem na discussão } \\
\text { sobre formação e atuação } \\
\text { profissional } \\
\text { Educação } \\
\text { Espósica em } \\
\text { e }\end{array}$} & \multirow{2}{*}{$\begin{array}{l}\text { Pesquisa qualitativa, } \\
\text { baseada em histórias } \\
\text { de vida de treinadores } \\
\text { de futebol. }\end{array}$} & \multirow{2}{*}{$\begin{array}{l}\text { As experiências como jogador } \\
\text { influenciaram na atuação } \\
\text { profissional do treinador, e os } \\
\text { conhecimentos oriundos do } \\
\text { curso de Educação Física foram } \\
\text { igualmente importantes para sua } \\
\text { atuação profissional. }\end{array}$} \\
\hline $\begin{array}{l}\text { Talamoni; } \\
\text { Hunger }\end{array}$ & & & \\
\hline $\begin{array}{l}\text { A olimpíada escolar e } \\
\text { a esportivização da } \\
\text { Educação Física no } \\
\text { Espírito Santo: } \\
\text { continuidades } \\
\text { descontinuidades }\end{array}$ & \multirow{2}{*}{$\begin{array}{lr}\text { Compreender a relação } \\
\text { da Olimpíada escolar e o } \\
\text { processo } & \text { de } \\
\text { esportivização } & \text { da } \\
\text { Educação Física. } & \end{array}$} & \multirow[t]{2}{*}{$\begin{array}{l}\text { Pesquisa descritiva e } \\
\text { documental. Utilizou } \\
\text { como fontes de } \\
\text { pesquisa jornais e } \\
\text { arquivo pessoal. }\end{array}$} & \multirow{2}{*}{$\begin{array}{l}\text { A olímpiada escolar surge da } \\
\text { necessidade de satisfazer os } \\
\text { impulsos competitivos dos } \\
\text { alunos, de contribuir para a } \\
\text { construção de valores sociais, } \\
\text { morais e de amor à pátria, além } \\
\text { de se configurar como uma } \\
\text { forma de dar visibilidade ao } \\
\text { esporte. }\end{array}$} \\
\hline Eller $\mathrm{N}$ & & & \\
\hline $\begin{array}{l}\text { Jogando com as } \\
\text { violências no esporte } \\
\text { de lazer: notas } \\
\text { etnográficas sobre o } \\
\text { "guri" e o "nego véio } \\
\text { da várzea" }\end{array}$ & \multirow{2}{*}{$\begin{array}{lr}\text { Compreender } & \text { as } \\
\text { dinâmicas } & \text { de } \\
\text { constituição das } & \text { noções } \\
\text { de violência } & \text { por } \\
\text { intermédio } & \text { de } \\
\text { personagens empíricos, } \\
\text { presentes em situações } \\
\text { de lazer. }\end{array}$} & \multirow[t]{2}{*}{ Pesquisa etnográfica. } & \multirow{2}{*}{$\begin{array}{l}\text { A violência mimética } \\
\text { desagradável não retrata } \\
\text { ruptura completa com a } \\
\text { configuração esportiva, mas sim } \\
\text { a discrepância derivada da falta } \\
\text { de sensibilidade nas avaliações } \\
\text { e nos deslizamentos entre as } \\
\text { distintas formas de jogar. }\end{array}$} \\
\hline $\begin{array}{l}\text { Myskiw; Mariante } \\
\text { Neto e Stigger }\end{array}$ & & & \\
\hline $\begin{array}{l}\text { (Re) pensando as } \\
\text { políticas públicas } \\
\text { esporte e lazer: } \\
\text { sociogênese } \\
\text { subcampo } \\
\text { político/burocrático } \\
\text { do esporte e lazer no } \\
\text { Brasil }\end{array}$ & \multirow{2}{*}{$\begin{array}{l}\text { Apresentar o histórico de } \\
\text { disputas no subcampo } \\
\text { político/burocrático do } \\
\text { esporte e lazer, } \\
\text { destacando aspectos que } \\
\text { possam contribuir para } \\
\text { reflexões acerca das } \\
\text { políticas públicas de } \\
\text { esporte e lazer no Brasil. }\end{array}$} & \multirow[t]{2}{*}{$\begin{array}{l}\text { Pesquisa qualitativa, } \\
\text { de cunho descritivo. }\end{array}$} & \multirow{2}{*}{$\begin{array}{l}\text { A intervenção do Estado no } \\
\text { campo esportivo ocorreu por } \\
\text { lógicas existentes no interior do } \\
\text { campo político/burocrático. A } \\
\text { incorporação desse campo se } \\
\text { deu sob a justificativa da } \\
\text { prevalência da lógica do Estado, } \\
\text { que passa a ser pautada por } \\
\text { interesses dos agentes } \\
\text { envolvidos com o esporte no } \\
\text { âmbito estatal. }\end{array}$} \\
\hline $\begin{array}{l}\text { Starepravo e Marchi } \\
\text { Júnior }\end{array}$ & & & \\
\hline $\begin{array}{l}\text { Possíveis } \\
\text { contribuições para os } \\
\text { estudos do lazer, a } \\
\text { partir da teoria do }\end{array}$ & $\begin{array}{l}\text { Analisar } \\
\text { contribuições para os } \\
\text { estudos de lazer a partir } \\
\text { da "teoria do processo }\end{array}$ & $\begin{array}{l}\text { Pesquisa de revisão } \\
\text { de literatura. }\end{array}$ & $\begin{array}{l}\text { O entendimento do lazer como } \\
\text { uma busca por excitação e } \\
\text { prazer, que por conta do } \\
\text { controle exercido sobre os }\end{array}$ \\
\hline
\end{tabular}


Adriely Gonçalves Orlando,

A Teoria Sociológica de Norbert Elias e a Produção Científica...

Fabiane Castilho Teixeira, Vinicius Machado de Oliveira,

Claudio Kravchychyn, Juliano de Souza

Ieda Parra Barbosa-Rinaldi

\begin{tabular}{|c|c|c|c|}
\hline processo civilizador & \multirow{2}{*}{$\begin{array}{l}\text { civilizador", de Norbert } \\
\text { Elias. }\end{array}$} & & \multirow[b]{2}{*}{$\begin{array}{l}\text { impulsos das pessoas não } \\
\text { podem ser manifestados na vida } \\
\text { cotidiana, apresentando também } \\
\text { as distinções entre os conceitos } \\
\text { de "tempo livre" e "lazer". }\end{array}$} \\
\hline $\begin{array}{l}\text { Nascimento } \\
\text { Marcellino }\end{array}$ & & & \\
\hline $\begin{array}{l}\text { Educação física, } \\
\text { futebol e gênero: uma } \\
\text { proposta de ensino a } \\
\text { partir das relações de } \\
\text { poder }\end{array}$ & \multirow{2}{*}{$\begin{array}{l}\text { Observar a configuração } \\
\text { social e as relações de } \\
\text { poder entre os gêneros e } \\
\text { a partir da } \\
\text { experimentação e } \\
\text { avaliação do futebol nas } \\
\text { turmas de } 4^{\circ} \text { e } 5^{\circ} \text { ano do } \\
\text { ensino fundamental, } \\
\text { embasadas no referencial } \\
\text { teórico de Elias. }\end{array}$} & \multirow{2}{*}{$\begin{array}{l}\text { Pesquisa qualitativa } \\
\text { de cunho descritivo, } \\
\text { com base na } \\
\text { pesquisa-ação. }\end{array}$} & \multirow{2}{*}{$\begin{array}{l}\text { O desinteresse pelo futebol está } \\
\text { associado à falta de habilidade } \\
\text { motora, aos aspectos históricos } \\
\text { e culturais. Além disso, } \\
\text { reflexões sobre os conceitos } \\
\text { como configuração e relações } \\
\text { de poder empregadas na } \\
\text { proposta de ensino } \\
\text { possibilitaram } \\
\text { alterações nas relações de } \\
\text { gênero. }\end{array}$} \\
\hline Nunes et al. & & & \\
\hline $\begin{array}{lr}\text { O processo de difusão } \\
\text { do kung fu } & \text { no } \\
\text { ocidente: entre } & \text { o } \\
\text { sentido de perda e } & \text { a } \\
\text { inevitabilidade } & \text { da } \\
\text { perda do sentido } & \end{array}$ & \multirow{2}{*}{$\begin{array}{l}\text { Problematizar aspectos } \\
\text { do processo do } \\
\text { desenvolvimento do } \\
\text { Kung Fu na China e de } \\
\text { sua posterior difusão } \\
\text { para o Ocidente à luz da } \\
\text { teoria de Norbert Elias. }\end{array}$} & \multirow{2}{*}{$\begin{array}{l}\text { Pesquisa } \\
\text { bibliográfica de } \\
\text { cunho histórico- } \\
\text { sociológico. }\end{array}$} & \multirow{2}{*}{$\begin{array}{l}\text { Alguns conceitos operacionais } \\
\text { da teoria de Norbert Elias foram } \\
\text { mobilizados para ampliar } \\
\text { campo de entendimento das } \\
\text { artes marciais e dos esportes de } \\
\text { combate. O conceito de } \\
\text { mimeses é mobilizado para } \\
\text { refletir sobre a reprodução da } \\
\text { realidade de maneira controlada } \\
\text { servindo de antídoto para as } \\
\text { tensões cotidianas. }\end{array}$} \\
\hline $\begin{array}{l}\text { Ferreira; Souza } \\
\text { Marchi Júnior }\end{array}$ & & & \\
\hline $\begin{array}{l}\text { Configurações e } \\
\text { relações estabelecidas } \\
\text { no estágio curricular } \\
\text { supervisionado de } \\
\text { Educação Física }\end{array}$ & \multirow{2}{*}{$\begin{array}{l}\text { Analisar } \\
\text { configurações existentes } \\
\mathrm{e} \text { as relações } \\
\text { estabelecidas (na } \\
\text { universidade e na escola) } \\
\text { entre os estagiários de } \\
\text { Educação Física (EF) e } \\
\text { os agentes da escola no } \\
\text { desenvolvimento do } \\
\text { Estágio Curricular } \\
\text { Supervisionado (ECS), a } \\
\text { partir dos diferentes } \\
\text { níveis de ensino da } \\
\text { Educação Básica. }\end{array}$} & \multirow[b]{2}{*}{$\begin{array}{l}\text { Pesquisa qualitativa e } \\
\text { quantitativa, de } \\
\text { cunho exploratório. } \\
\text { Utilizou } \\
\text { questionários. }\end{array}$} & \multirow{2}{*}{$\begin{array}{l}\text { Na configuração do ECS, a } \\
\text { universidade e a escola } \\
\text { apresentam encadeamento } \\
\text { interdependente. As relações } \\
\text { entre estagiários, professores } \\
\text { orientadores, professores } \\
\text { supervisores e demais agentes } \\
\text { da escola referendam o } \\
\text { posicionamento Elias frente à } \\
\text { importância das configurações } \\
\text { de indivíduos interdependentes. }\end{array}$} \\
\hline $\begin{array}{l}\text { Silva-Júnior; Both e } \\
\text { Oliveira }\end{array}$ & & & \\
\hline $\begin{array}{l}\text { Os árbitros de futebol } \\
\text { e a mídia esportiva: a } \\
\text { interpretação de } \\
\text { árbitros paulistas } \\
\text { sobre os comentários } \\
\text { da mídia acerca do } \\
\text { trabalho da equipe de } \\
\text { arbitragem }\end{array}$ & \multirow{2}{*}{$\begin{array}{l}\text { Compreender como os } \\
\text { árbitros entrevistados } \\
\text { sentem e interpretam os } \\
\text { comentários feitos na } \\
\text { mídia a respeito da } \\
\text { atuação da equipe de } \\
\text { arbitragem durante uma } \\
\text { partida de futebol. }\end{array}$} & \multirow[t]{2}{*}{$\begin{array}{l}\text { Pesquisa qualitativa, } \\
\text { de cunho descritivo. } \\
\text { Utilizou entrevista } \\
\text { semiestruturada. }\end{array}$} & \multirow{2}{*}{$\begin{array}{l}\text { Para os árbitros, os comentários } \\
\text { da mídia sobre as suas decisões } \\
\text { em lances duvidosos } \\
\text { polêmicos no jogo são } \\
\text { desumanos, uma vez que os } \\
\text { jornalistas e comentaristas } \\
\text { possuem recursos de análises } \\
\text { não disponíveis aos mesmos. } \\
\text { Interpretam a violência como } \\
\text { falta de respeito, de capacidade } \\
\text { de dialogar, entre outros, } \\
\text { enquadrando-se na categoria } \\
\text { violência simbólica de Elias. }\end{array}$} \\
\hline Righeto e Reis & & & \\
\hline
\end{tabular}

Fonte: Os autores 
Dentre os 16 artigos analisados, oito apresentam a abordagem qualitativa, dois apresentam a abordagem qualitativa/quantitativa e seis não trazem esta informação. Adicionalmente, verificamos nove pesquisas do tipo descritiva, três do tipo bibliográfica, uma do tipo etnográfica, uma do tipo documental, uma do tipo revisão de literatura e uma do tipo exploratória.

Vale pontuar que a abordagem qualitativa envolve significados e valores no ato de compreender os fatos sociais, em uma dinâmica que não pode ser traduzida em números ou análises estatística (MINAYO, 2010). Outro aspecto que se destaca é a variedade de fonte de dados empregada nas pesquisas em questão. Verificamos a aplicação de questionários, análises de jornais, análises de revistas, análises bibliográficas e relatos de história de vida.

Ao analisar a presença dos conceitos eliasianos nos artigos encontrados, evidenciamos a possibilidade de contemplá-los a partir de eixos temáticos específicos da Educação Física, sendo estes: Esporte (10 artigos), Formação profissional (3 artigos), Lazer (3 artigos), Esporte/Lazer (2 artigos), Políticas Públicas de Esporte e Lazer (2 artigos) e História da Educação Física (1 artigo).

Mais um ponto a ser mencionado é a preocupação dos autores em empregar a referente teoria para explicar as relações entre sociedade e objetos de análise caros à Educação Física. A contribuição da teoria eliasiana, nesse sentido, se dá por refinar o entendimento das ações, fatos, atividades e situações pertinentes ao contexto da Educação Física e do esporte, primando pela condição realista de que a sociedade deve ser dimensionada como estrutura que não são é exterior aos atores sociais, já que os indivíduos são simultaneamente cercados pela sociedade e separados dela por uma barreira invisível (ELIAS, 2008). 
Vale mencionar, portanto, que a relevância da teoria de Elias ocorre pelos subsídios concretos e realistas que oferece ao tratamento de problemáticas sociais e que o mapeamento que realizamos, de certa forma, remete à essa premissa, uma vez que os objetos de pesquisa tematizados nos artigos revisitados em nossa amostragem final foram construídos com essa preocupação. $\mathrm{Na}$ sequência, apresentamos e problematizamos os principais conceitos da teoria de Elias mobilizados nos artigos que compuseram nosso cenário de investigação.

\section{Produções Científicas em Educação Física e a Apropriação de Conceitos da Teoria de Elias}

Importante destacar inicialmente que, o material que consultamos para compor nossa investigação mobiliza mais que um único conceito de Elias em suas discussões e análises. A Tabela 1 apresenta os principais conceitos identificados nos estudos.

Tabela 1: Identificação dos principais conceitos da teoria de Elias empregados na produção científica em Educação Física

\begin{tabular}{cc}
\hline Conceitos & Frequência \\
\hline Teias de interdependência & 12 \\
Processo civilizador & 8 \\
Atividades miméticas & 5 \\
Tensão-excitação & 4 \\
\hline
\end{tabular}

Fonte: os autores

Outros conceitos, não menos importantes foram também visualizados em nossa busca, a saber: poder ( $f 3)$, conflito $(f 3)$, emoções $(f 2)$, escape $(f 1)$, violência $(f 1)$, autonomia relativa $(f 1)$, competição $(f 1)$. Nossa análise se centrou, entretanto, naqueles conceitos que apareceram com maior frequência e destaque nas pesquisas localizadas. 


\section{Teias de Interdependência}

Como verificado a partir da análise frequencial, o conceito Teias de interdependência apareceu com maior frequência (f12) entre os estudos selecionados. Para Elias esse conceito ajuda a explicar como os seres humanos estão conectados uns aos outros, já que a sociedade é constituída por configurações que não são alheias aos indivíduos singulares, sendo que o movimento inverso complementa esta relação (ELIAS, 2008). Nesse sentido, as estruturas sociais não podem ser lidas de maneira desconexa à ação social, pois, ambas estão imbricadas e ajudam a promover uma leitura mais global da sociedade e dos indivíduos.

Ao relacionar teias de interdependência e esporte, em específico o caso do futebol, Valentin e Cavichiolli (2007), empregam esse conceito para explicitar os tipos de relações presentes nos jogos de bairro e a atuação dessas relações no esporte e na sociedade como um todo. Para tratar do futebol de bairro como prática esportiva, os pesquisadores realizam análises dos depoimentos dos praticantes e, a partir do conceito de teias de interdependência, verificam que a prática esportiva e as relações estabelecidas com o outro promovem no indivíduo formas, meios e ações para liberar suas tensões e excitações.

De acordo com Pimenta e Marchi Júnior (2009), compreender o Taekwondo como esporte moderno implica o entendimento das relações estabelecidas com o contexto social. Por meio deste conceito, os pesquisadores verificam que até aqueles que possuem maior autonomia no campo esportivo, o qual eles denominam de agenciadores de capitais, estão inclusos em redes de interdependências, permanecendo então em constante dependência dos outros. 
Talamoni; Oliveira e Hunger (2013) empregaram o conceito de teias de interdependência para entender como se deu o processo de formação e atuação de treinadores de futebol, no propósito de verificar quais as configurações e relações foram efetivadas no percurso até a atuação profissional, além de observar as configurações existentes entre treinador e atleta ou entre treinador e ambiente social.

As pesquisas desenvolvidas por Souza; Starepravo e Marchi Júnior (2011) e Souza e Marchi Júnior (2013) indicam a possibilidade de aplicação do referido conceito para explicar as interligações presentes entre indivíduos e sociedade. Souza; Starepravo e Marchi Júnior (2011) buscam compreender as relações estabelecidas entre os processos de mercantilização e espetacularização dos passatempos presentes no interior das sociedades inglesa e norte-americana, para demonstrar a definição esportiva do xadrez e para a elaboração de uma definição mais polissêmica de esporte. No estudo de Souza e Marchi Júnior (2013), o aspecto central em relação ao conceito de interdependências é que as relações estabelecidas entre os agentes no subcampo do xadrez não se dão apenas quando há alianças, mas também quando as pessoas rivalizam, sendo o poder o elemento mediador dessa dinâmica.

O emprego da teoria de Elias motivou também Góis Junior; Lovisolo e NistaPiccolo (2013) a investigarem a superficialidade que incide sobre o emprego dessa teoria na área da história da Educação Física. Percebe-se a ampliação da aplicação de conceitos de Elias para explicar relações estruturais e configuracionais entre atores sociais e instituições. Porém, o estudo evidencia a ausência de critérios de análise para fazer uso da presente teoria.

Por sua vez, Starepravo; Souza e Marchi Júnior (2012) apontam que a teoria de Elias traz contribuições para o estudo das políticas públicas de esporte e lazer, 
principalmente no que concerne o entendimento das estruturas, das relações e do poder atrelado a esse campo específico. Ainda sobre o campo político, Starepravo e Marchi Júnior (2016), destacam que algumas relações são mais complexas que outras, de modo que é importante considerar a distribuição de poder como um dos principais elementos que promovem interligações e teias de interdependências entre os indivíduos de uma mesma sociedade.

No entendimento de Righeto e Reis (2017), os seres humanos pertencentes a diferentes grupos sociais precisam relacionar-se e comunicar-se uns com os outros. Nesse sentido, o futebol é visto como um meio em potencial para unir as pessoas que delem fazem parte, a partir de uma figuração social que promove de forma dinâmica as interconexões com outros indivíduos de diferentes segmentos sociais e afetivos.

Silva-Júnior; Both e Oliveira (2018) mobilizaram os conceitos de jogo, configuração e relações de poder de Elias para discutirem as relações estabelecidas no desenvolvimento do Estágio Curricular Supervisionado (ECS). Nesse sentido, com o subsídio dos referentes conceitos, os autores da pesquisa buscaram esclarecer as interconexões estabelecidas entre o futuro professor de educação física, (estagiário) com o professor orientador, com o professor supervisor, bem como com os demais agentes da escola e da universidade. Além disso, o ECS se materializa como um jogo que permite aos estagiários ampliarem suas possibilidades de exercer com maior autonomia suas ações frente ao contexto de atuação. Portanto, este processo apresenta um conjunto de interdependências e todas as relações estabelecidas são consideradas elementos constituintes de um determinado meio social.

Ao abordarem o processo de difusão do Kung Fu, Ferreira; Souza e Marchi Júnior (2017) empregaram conceitos de Elias para ampliar o entendimento acerca do 
campo das artes marcais e dos esportes de combate. Nessa perspectiva, os autores ressaltam que não são necessários grupos extensos para que ocorram as relações de interdependência, uma vez que apenas alguns indivíduos treinando já são capazes de construir uma cadeia de relações interdependentes. Portanto, todas as modificações ocorridas nos indivíduos que os levassem ao maior autocontrole e ao avanço dos padrões antigos de comportamento estavam diretamente ligadas à distribuição do poder nas teias de interdependência.

Na pesquisa de Nunes et al. (2014), a teoria eliasiana subsidiou os autores na observação das configurações sociais e as relações de poder existentes entre os gêneros na educação física escolar, tomando como caso investigativo o futebol. Os resultados apontaram maior interesse dos meninos pela prática esportiva do futebol e, em contrapartida, a exclusão das meninas à prática dessa modalidade no contexto escolar.

\section{Processo Civilizador}

O termo Processo Civilizador aparece como o segundo conceito mais empregado pelos autores (f8). De acordo com Elias (2011), o processo civilizador indica como ao longo dos séculos, na escala de longo prazo, o comportamento dos indivíduos foi sendo alterado de modo que a sociedade também passou por mudanças em função dos códigos de conduta estabelecidos no tecido social. Em outras palavras, com o exercício das relações ao longo do tempo, os hábitos dos seres humanos foram sendo refinados e as condutas que antes, em alguma medida, eram toleradas, a exemplo da violência, passaram a ser recriminadas.

Mas vale destacar, que tal processo não afeta apenas os seres humanos, como também as estruturas, a propósito da formação do Estado moderno tal como discutido 
por Elias no segundo volume de O processo civilizador (1993). Pautando essa lógica, os artigos que compõem nossa amostragem final dão tratamento à dimensão processual dos fenômenos sociais.

Valentin e Cavichiolli (2007), por exemplo, se apropriaram do conceito do Processo Civilizador para tratar a prática esportiva (futebol) como forma de escape e prática social. A partir do momento em que o indivíduo consegue dividir seu tempo conciliando suas tarefas com momentos de escape, é possível pensar que tenha encontrado formas de atenuar à aridez das atividades cotidianas que exigem um alto grau de autocontrole. Seguindo essa perspectiva, Pimenta e Marchi Júnior (2009) demonstraram que o processo de civilização proposto por Elias aponta para o desenvolvimento da sociedade e dos indivíduos que nela se inserem. Tratando especificamente das artes marciais, os autores indicam que a sociedade precisou se adaptar e se autocivilizar para responder às demandas existentes e às mudanças necessárias.

Ainda nesse sentido, Nascimento e Marcellino (2012), se apropriam do conceito de Processo Civilizador entendem a prática do lazer como uma forma de escape. Entende-se que a prática do lazer promove excitação e prazer aos seus praticantes, que não liberam suas tensões e impulsos no dia-a-dia devido a vida cotidiana.

Levando em consideração este modo de entendimento e apropriação da teoria de Elias, Souza; Starepravo e Marchi Júnior (2011) mobilizaram a teoria eliasiana para explicar como e por que se deu o processo de esportivização do xadrez em meados do século XIX. Desde seu surgimento, essa prática teve seu espaço dentro da sociedade e, só tardiamente, apresentou nuanças de esportivização em correspondência com a dinâmica do processo civilizador. 
Além dos autores supracitados, Eller et al. (2015), também abordam a compreensão da esportivização por intermédio do referencial teórico em tela. Nesse estudo, os autores buscam compreender a lógica de esportivização da Educação Física no Espírito Santo e a contribuição das Olimpíadas Escolares para esse processo, tendo como base o entendimento da teoria para verificar as relações necessárias a efetivação da esportivização no estado.

Góis Junior; Lovisolo e Nista-Piccolo (2013), estudando a Teoria do Processo Civilizador no campo da história da Educação Física, verificaram por meio da produção de conhecimento, que a aplicação da teoria de Elias ainda insurge de forma superficial na literatura. Ademais, os pesquisadores defendem a potencialidade da Teoria do Processo Civilizador para apreensão historiográfica de objetos caros à Educação Física, especialmente nas investigações de longa e longuíssima duração.

Já Myskiw; Mariante Neto e Sttiger (2015), ao retomarem o futebol de várzea, apontam que o processo civilizador é central para o desenvolvimento da sociedade, porém atividades de lazer como o futebol podem contribuir para externalização de tensões não toleradas nas rotinas de seriedade. Em alguma medida, a violência mimética que ocorre nos campos de futebol de várzea é tolerável, mas em alguns momentos essa violência, embora mimética, pode se tornar desagradável, o que, de certo modo, representa um impulso descivilizador.

Por fim, Starepravo e Marchi Júnior (2016) também se apropriaram da noção de Processo Civilizador, mais especificamente do conceito de sociogênese que Elias apresentou em sua teoria, para buscar compreender como as mudanças sociais e de comportamento impactaram nas estruturas sociais, promovendo reflexões acerca das políticas públicas do esporte e lazer no Brasil. 


\section{Atividades Miméticas}

Outro conceito observado nos estudos revisitados (f5), foi o de Atividades Miméticas, que se refere mais especificamente ao termo mimese utilizado por Elias para definir as atividades que podem reproduzir em escala micro, situações próximas à realidade macrossocial. Essas atividades são reconhecidas pela capacidade de proporcionar emoções e tensões aos praticantes, quer dizer, uma excitação controlada, equilibrada e agradável que encoraja outras sensações acionadas livremente como efeito libertador e catártico em um ambiente mais controlado e com atenuação dos riscos (ELIAS; DUNNING, 1992).

Nos trabalhos de Valentin e Cavichiolli (2007) e de Reis e Cavichiolli (2008), os autores empregam o conceito de Atividades Miméticas a partir da mesma perspectiva, em objetos de análise específicos. No primeiro estudo, que aborda a prática do futebol de bairro, os autores identificam que o futebol praticado nas comunidades contribui para a produção de uma tensão-prazer nos indivíduos, instituindo um equilíbrio entre as rotinas de seriedade e as atividades de lazer. Nesse mesmo sentido, o segundo estudo dimensiona os jogos eletrônicos como atividades potenciais para a produção de tensãoexcitação, demonstrando que esses jogos recriam determinadas situações em ambientes controlados e seguros.

Já Myskiw; Mariante Neto e Sttiger (2015) contemplam o contexto mimético sob outro ângulo. Os autores discorrem sobre as violências desagradáveis (no âmbito do controle dos indivíduos envolvidos) como um fator contribuinte para a prática de atividade mimética. Nesse sentido específico, é possível afirmar que os surtos de violência promovem aos seus praticantes picos intensos de desequilíbrios entre suas tensões-excitações. 
Por sua vez, Souza e Marchi Júnior (2013) ao correlacionarem a Guerra Fria com a final do Campeonato Mundial de Xadrez de 1972 se reportam a aspectos da teoria dos jogos competitivos de Elias (2008), de modo a analisar como uma competição de tabuleiro recria sob prisma mimético, e sem tantos perigos físicos, o cenário de confronto entre extremos, traduzindo, portanto, o acirramento político de uma época.

Para Reis e Cavichiolli (2008), o que cada indivíduo procura em uma atividade de lazer é o prazer, sendo esse proporcionado por um pico de excitação, que proporciona sensações satisfatórias aos indivíduos. Assim, as pessoas buscam vivenciar e experimentar as mais diversas emoções, procurando estabelecer um equilíbrio entre controle dos impulsos com a externalização das tensões não permitidas no contexto social civilizado.

Para Ferreira; Souza e Marchi Junior (2017), o Kung Fu pode ser visto como instrumento que potencializa a descarga emocional dos praticantes, o qual oferece por meio dos combates simulados, exercícios específicos ou até mesmo competições que permitem extravasar emoções, sem grandes danos e sem ultrapassar os limites sociais. O conceito de mimesis é empregado para demonstrar a reprodução da realidade de maneira controlada, que permite extravasar e transferir a tensão diária no âmbito e espaço da prática do Kung $\mathrm{Fu}$, servindo de antídoto para estas tensões. Nessa perspectiva, as artes marcais têm como um dos seus objetivos permitir aos praticantes reestabelecerem seus níveis de tensão e emoção de forma agradável.

\section{Tensão-Excitação}

Somado à noção de mimesis, o conceito Tensão-excitação também é fundante para a compreensão das atividades esportivas e de lazer no que concerne o plano das 
emoções. Por isso, o conceito de Tensão-excitação é bastante mobilizado nos estudos sociais do esporte desenvolvidos na perspectiva eliasiana. As tensões e excitações estão presentes em vários momentos da vida, podendo se manifestar em diferentes intensidades de acordo com as situações produzidas (ELIAS; DUNINNG, 1992). Sendo assim, em nossa análise o conceito aparece em quatro dos 11 artigos selecionados (f4).

$\mathrm{Na}$ esteira do que está sendo posto, os estudos de Valentin e Cavichiolli (2007) e Reis e Cavichiolli (2008) adotam a categoria Tensão-excitação para explicar a prática esportiva do futebol e a prática de jogos eletrônicos como formas de excitação e restauração das tensões. No primeiro trabalho, os autores analisam a prática esportiva do futebol masculino como meio de escape para liberações de tensões, se configurando, portanto, o futebol de bairro como uma das principais práticas a autorizar a tensãoexcitação dos indivíduos nas comunidades. Já o segundo trabalho sinaliza para uma prática que detém o mesmo objetivo de liberação de tensões acumuladas, só que por via dos jogos eletrônicos.

Já Souza e Marchi Júnior (2013), se apropriam do referido conceito para sinalizar a possível excitação mimética ocorrida durante o "match do século", caracterizada pelo confronto entre os enxadristas Boris Spassky e Robert James Fischer, associando uma disputa no subcampo esportivo do xadrez aos tensionamentos da Guerra Fria protagoniza por Estados Unidos e antiga União Soviética. Para os pesquisadores, esse confronto simbólico gerou, em alguma medida, uma excitação pela associação com o contexto de guerra.

Por fim, Myskiw; Mariante Neto e Sttiger (2015), tematizam em seu trabalho os momentos de pico produzidos pelo lazer de tensão-excitação durante a prática de 
futebol, por intermédio de sensações, medos e tensões, isto é, de jogos dramaticamente vividos com intensidades e frequências moderadas e instáveis.

\section{Conclusões}

A partir da presente revisão sistemática, pudemos constatar que os pesquisadores da subárea sociocultural em Educação Física no Brasil têm empregado em suas investigações os conceitos do referencial teórico eliasiano como elemento potencializador de suas análises, tentando colocar em prática o exercício de correlação entre os conceitos da teoria com objetos e problematizações presentes no âmbito da Educação Física. Todavia, nem todos os conceitos são acionados relacionalmente nos trabalhos, evidenciando que os pesquisadores se utilizam daqueles que melhor se adequam às suas necessidades de análise.

Dessa forma, a pesquisa aqui desenvolvida observou a relevância e abrangência da teoria em questão para dar sustentação teórica e subsidiar os pesquisadores da área no tratamento de seus objetos de estudo. Entretanto, acreditamos que o processo de apropriação da teoria está em curso, pois embora os esforços de mobilização dos conceitos sejam notáveis nos estudos revisitados, há ainda muito o que se absorver da teoria, em particular no propósito de fazer valer o desenvolvimento de abordagens de longo prazo e que procurem concatenar tendências paralelas de ordem micro e macrossociológica como prioridades investigativas no campo da Sociologia do Esporte e da Educação Física.

Para além, no entanto, da ideia de explicitar supostas insuficiências no processo de apropriação do referencial teórico em questão, a conclusão principal deste artigo é que apesar de a comunidade científica da Educação Física no Brasil operar com os 
conceitos teóricos de Norbert Elias, conforme explicitado nos artigos que compuseram nossa revisão sistemática, o alcance deste referencial na área enfatiza à análise, sobretudo, do fenômeno esportivo, estando, portanto, esse quadro em aberto para subsidiar o tratamento de questões tangenciais do campo da Educação Física no Brasil.

\section{REFERÊNCIAS}

BARDIN, L. Análise de conteúdo. 4. ed. Lisboa: Edições 70; 2011.

ELIAS, N. Introdução à sociologia. Tradução de Maria Luísa Ribeiro Ferreira. Lisboa: Edições 70, 2008.

. O processo civilizador: Formação do Estado e civilização. Tradução de Ruy Jungmann. Rio de Janeiro: Jorge Zahar, 1993. v. 2.

. O processo civilizador: Uma história dos costumes. Tradução: Ruy Jungmann. Revisão e apresentação: Renato Janine Ribeiro. 2. ed. Rio de Janeiro: Zahar, 2011.

.; DUNNING, E. A busca da Excitação. Tradução: Maria Manuela Almeida e Silva. Revisão e apresentação: Maria Manuela Vieira e Ayla Monteiro. Lisboa: Difusão, 1992.

ELLER, M.L et al. A olimpíada escolar e a esportivização da educação física no Espírito Santo: continuidades e descontinuidades. Revista de Educação Física - UEM, v. 26, n. 03, p. 379-400, 2015.

FERREIRA, F. D. C.; SOUZA, J. de.; MARCHI JÚNIOR, W. O processo de difusão do Kung Fu no Ocidente: entre o sentido de perda e a inevitabilidade da perda do sentido. Motrivivência, v. 29, n. 51, p. 13-27, 2017.

GÓIS JUNIOR, E.; LOVISOLO, H.R.; NISTA-PICCOLO, V.L. Processo civilizador: Apontamentos metodológicos na historiografia da educação física. Revista Brasileira de Ciências do Esporte, v. 35. n. 03, p. 773-783, 2013.

GOMES, I.S.; CAMINHA, I.O. Guia para estudos de revisão sistemática: uma opção metodológica para as ciências do movimento humano. Revista Movimento, v. 20, n. 01, p. 395-411, 2014.

MEDEIROS, C.C.C.; GODOY, L. As referências de Pierre Bourdieu e Norbert Elias na Revista Brasileira de Ciências do Esporte: mapeando tendências de apropriação e de produção de conhecimento na área da Educação Física (1979-2007). Revista Brasileira de Ciências do Esporte, v. 30, n. 02, p. 199-214, 2009.

MINAYO, M.C.S. Pesquisa Social: teoria, método e criatividade. 29. ed. Petrópolis: Vozes, 2010. 
MYSKIW, M.; MARIANTE NETO, F.P.; STIGGER, M.P. Jogando com as violências no esporte de lazer: notas etnográficas sobre o "guri" e o "nego véio da várzea". Revista Movimento, v. 21, n. 04, p. 889-902, 2015.

NASCIMENTO, R. M., MARCELINO, N. C. Possíveis contribuições para os estudos do lazer, a partir da teoria do processo civilizador. Licere, v. 15, n. 01, p. 01-15, 2012.

NUNES, H. F. P.; PIMENTA, T. F. F.; CESANA, J.; DRIGO, A. J. Educação física, futebol e gênero: uma proposta de ensino a partir das relações de poder. Pensar a prática, v. 17, n. 04, p. 01-14, 2014.

PIMENTA, T.; MARCHI JÚNIOR, W. A constituição de um subcampo do esporte: o caso do Taekwondo. Revista Movimento, v. 15, n. 01. p.193-215, 2009.

REIS, L.J.A.; CAVICHIOLLI, R.F. Jogos eletrônicos e a busca da excitação. Porto Alegre: Revista Movimento, v. 14, n. 03, p. 163-183, 2008.

RIGHETO, C.; REIS, H. H. B. Os árbitros de futebol e a mídia esportiva: a interpretação de árbitros paulistas sobre os comentários da mídia acerca do trabalho da equipe de arbitragem. Revista Movimento, v. 23, n. 01, p. 281-294, 2017.

SILVA, J.A.; CERRI, L.F. Norbert Elias e Pierre Bourdieu: biografia, conceitos e influências na pesquisa educacional. Revista Linhas, v.14, n. 26, p.171-198, 2013.

SILVA- JÚNIOR, A. P. da S.; BOTH, J.; OLIVEIRA, A. A. B. de.; Configurações e relações estabelecidas no estágio curricular supervisionado de educação física. Journal of Physical Education, v. 29, p. 29-37, 2018.

SOUZA, J.; MARCHI JÚNIOR, W. A guerra fria e a final do campeonato mundial de xadrez de 1972: algumas possibilidades analíticas e correlacionadas. Revista Brasileira de Educação Física e Esporte, v. 27, n. 04, p. 567-581, 2013.

SOUZA, J.; STAREPRAVO, F.A.; MARCHI JÚNIOR, W. O Processo de constituição histórico-estrutural do subcampo esportivo do xadrez: uma análise sociológica. Revista Movimento, v. 17, n. 02, p. 93-113, 2011.

STAREPRAVO, F.A.; MARCHI JÚNIOR, W. (Re) pensando as políticas públicas de esporte e lazer: a sociogênese do subcampo político/burocrático do esporte e lazer no Brasil. Revista Brasileira de Ciências do Esporte, v. 38, n. 01, p. 42-49, 2016.

; SOUZA, J.; MARCHI JÚNIOR, W. A teoria dos jogos competitivos de Norbert Elias como alternativa à leitura das políticas públicas de esporte e lazer no Brasil. Revista Brasileira de Educação Física e Esporte, v. 26, n. 04, p. 657-665, 2012.

TALAMONI, G.A.; OLIVEIRA, F.I.S.; HUNGER, D. As configurações do futebol brasileiro: análise da trajetória de um treinador. Revista Movimento, v. 19, n. 01, p. 7393, 2013. 
THOMAS, J.R.; NELSON, J.K.; SILVERMAN, S.J. Métodos de pesquisa em atividade física. 6. ed. Porto Alegre: Artmed, 2012.

VALENTIN, R.B; CAVICHIOLLI, F.R. Futebol, escape e mímesis: um estudo sobre representações sociais. Revista Movimento, v.13, n. 03. p. 65-89, 2007.

\section{Endereço dos Autores:}

Adriely Gonçalves Orlando

Universidade Estadual de maringá

Departamento de Educação Física

Av. Colombo, 5790 / Bloco M06 - Sala 15 - Campus Universitário

Maringá - PR - 87.020-900

Endereço Eletrônico: adrielyorlando@hotmail.com

Fabiane Castilho Teixeira

UNICESUMAR

Av. Guedner 1610 - jardim Aclimação

Maringá - PR - 87.050-900

Endereço Eletrônico: fabianecteixeira@gmail.com

Vinicius Machado de Oliveira

Universidade Estadual de Maringá

Departamento de Educação Física

Av. Colombo, 5790 / Bloco M06 - Sala 15 - Campus Universitário

Maringá - PR - 87.020-900

Endereço Eletrônico: oliveira_vm@hotmail.com

Claudio Kravchychyn

Universidade Estadual de Maringá

Departamento de Educação Física

Av. Colombo, 5790 / Bloco M06 - Sala 15 - Campus Universitário

Maringá - PR - 87.020-900

Endereço Eletrônico: claudiokrav@gmail.com

Juliano de Souza

Universidade Estadual de Maringá

Departamento de Educação Física

Av. Colombo, 5790 / Bloco M06 - Sala 15 - Campus Universitário

Maringá - PR - 87.020-900

Endereço Eletrônico: julianoedf@yahoo.com.br

Ieda Parra Barbosa-Rinaldi

Universidade Estadual de Maringá

Departamento de Educação Física

Av. Colombo, 5790 / Bloco M06 - Sala 15 - Campus Universitário

Maringá - PR - 87.020-900 
Adriely Gonçalves Orlando,

A Teoria Sociológica de Norbert Elias e a Produção Científica... Fabiane Castilho Teixeira, Vinicius Machado de Oliveira,

Claudio Kravchychyn, Juliano de Souza

Ieda Parra Barbosa-Rinaldi

Endereço Eletrônico: parrarinaldi@hotmail.com 